\title{
DOS PROJETOS INTEGRACIONISTAS EUROPEUS AO CONGRESSO ANFICTIÔNICO DO PANAMÁ
}

\author{
Paulo Alves Pereira Júnior* \\ Universidade Estadual Paulista "Júlio de \\ Mesquita Filho" \\ Assis - São Paulo - Brasil
}

Resenha do livro: REZA, Germán A. de la. A invenção da paz: da República cristã do duque de Sully à Federação das Nações de Simón Bolívar. Tradução de Jorge Adelqui Cáceres Fernández e André Figueiredo Rodrigues. São Paulo: Humanitas, 2015, 178 p.

Ganhadora do prêmio Pensamiento de América (2008-2010), La invención de la paz foi publicada em 2009 pela editora mexicana Siglo XIX. Escrita por Germán A. de la Reza, doutor em Ciências Econômicas pela Universidade Paris I e em Filosofia e História pela Universidade Toulose Le Mirail, a obra ganhou edições em diferentes idiomas. Em 2015, foi lançada pela editora brasileira Humanitas, traduzida por André Figueiredo Rodrigues - professor do curso de História da Universidade Estadual Paulista - e Jorge Adelqui Cáceres Fernández.

\footnotetext{
* Mestrando em História pela Faculdade de Ciências e Letras da Universidade Estadual Paulista "Júlio de Mesquita Filho" (Unesp), campus de Assis. E-mail: paulopereira_pf@hotmail.com.
} 
Fracionado em onze capítulos, o livro tem como escopo a análise das relações intelectuais e das circulações de ideais relacionadas aos projetos confederativos na Europa e na América Latina. Para isso, avança em duas direções que se entrecruzam: a identificação dos elementos que permeiam as propostas de República cristã e as origens do empreendimento unionista idealizado por Simón Bolívar. A partir de tais objetivos, o estudo estabelece uma linha que conecta o ideário anfictiônico greco-romano ao europeu e, posteriormente, ao latino-americano.

Procurando entender as convicções confederativas, Germán A. de la Reza analisa o projeto de transmissão-recepção - diferenciando o contexto histórico de cada um - de cinco pensadores: Felipe II da Macedônia, Maximilien de Béthune (duque de Sully), Charles-Irénée Castel (abade de Saint Pierre), JeanJacques Rousseau e Simón Bolívar. Apesar de privilegiar tais autores, Germán também destaca certas ideias de Émeric Crucé, Hugo Grocio, Emmanuel Kant, Claude-Henri de Rouvroy (conde de Saint-Simon), Cecílio del Valle, Silvestre Pinheiro Ferreira e Lucas Alamán.

Entre os séculos VI a. C. e II d. C., a civilização grega realizou as primeiras ligas de povos, com o propósito de normatizar as relações existentes entre as tribos das nações unificadas. Os delegados eram eleitos pelo voto popular e tais federações possuíam funções políticas e/ou religiosas, dependendo de cada comunidade. Inspirado por esse modelo, o rei Felipe II da Macedônia organizou, no ano de 388 a. C., a Liga Helênica, com sede em Corinto. Existindo até 280 a. C., tal federação tinha como objetivo a discussão sobre assuntos relacionados à paz geral, à união pan-helênica e à manutenção da unidade interna. Cada representante era eleito pela entidade e os delegados podiam tomar decisões vinculantes. A longevidade e as estruturas organizacionais das tentativas de unificação da Grécia influenciaram o pensamento político e jurídico da Europa e da América Latina em distintos momentos históricos.

No atual território francês, entre 1639 e 1640, foram publicadas - no Castelo Loire - as primeiras edições de Memórias das sábias e reais economias do estado, domésticas, políticas e militares de Henrique, o Grande. Escrita pelo conde de Sully, essa amálgama de história nacional com crônica palaciana propunha a criação de uma estrutura comum de República cristã formada por todos os senhorios, Estados e reinos cristãos da Europa. Sully também recomendava a elaboração de uma arbitrariedade internacional que garantisse a paz entre os membros associados, administrada por um congresso de delegados renovado a cada três anos. Apesar de ser um esquema que pretendia resolver os problemas envolvendo as nações europeias a curto, médio e lon- 
go prazo, a obra de Sully contribuiu para a criação de uma corrente do pensamento jurídico e político que inspirou os projetos anfictiônicos vindouros.

Em Paris, entre 1712 e 1717, foram publicados os três volumes do Projeto para fazer a paz perpétua na Europa, escritos pelo abade de Saint Pierre. Discutiuse, nesse projeto, a criação de uma comunidade perpétua entre as nações europeias que debatesse a elaboração de um sistema de paz inalterável, o amparo do status quo territorial, a abdicação do acúmulo de poder e a criação de um "Senado da Europa", composto por delegados do continente. Tal projeto foi o mais popular da corrente anfictiônica e influenciou outros pensadores na Europa e na América.

Devido ao sucesso editorial da obra de Saint Pierre, Jean-Jacques Rousseau elaborou um trabalho que consistia na simbiose entre os pensamentos do abade e seus comentários sobre tais teses. Lançado em 1761 com o título Extrato do projeto de paz perpétua do senhor abade de Saint Pierre, Rousseau idealizou a confederação dos povos como uma assembleia formada por representantes preocupados com o "sentimento comum". Além disso, discorreu sobre as vantagens na criação de um tribunal supranacional, como a certeza de que os litígios seriam resolvidos sem a necessidade de conflitos bélicos, a redução ou o fim das despesas militares, o progresso da agricultura, o bem-estar da população e o aumento das riquezas dos governantes. Ao resumir e comentar as ideias de Saint Pierre, Rousseau promoveu ambas as obras e fez com que fossem relevantes para a filosofia política no período de transição do século XVIII para a centúria seguinte.

Inspirado nas ideias de Saint Pierre - difundidas por Rousseau -, Simón Bolívar convocou, em 1824, a Grande Colômbia, a Federação Centro-Americana, o México, o Peru, os Estados Unidos, a Bolívia, a Inglaterra e os Países Baixos para participarem do Congresso Anfictiônico do Panamá. De 22 de junho a 15 de julho de 1826, os representantes dos países que lograram chegar a tempo discutiram assuntos referentes à publicação de um documento que denunciasse as atitudes da Espanha, a assinatura de um tratado de livre comércio e de navegação e o processo de abolição da escravidão no território confederado.

Após o término do evento, uma parte do congresso transladou-se ao México para prosseguir com as negociações, enquanto a outra partiu para suas respectivas nações com o propósito de ratificar os tratados. Com exceção da Grande Colômbia, nenhum outro Estado aprovou tais medidas. Dessa forma, o primeiro ensaio de integração entre as nações latino-americanas malogrou. A experiência dessa tentativa e os ideais bolivarianos dispersados na região possibilitaram a realização de três congressos entre 1847 e 1865. Após o fracasso de tais iniciativas, o ideário unionista encerrou-se no conti- 
nente e os países latino-americanos concentraram-se em promover questões relacionadas à arbitragem internacional.

Com a finalidade de discutir sobre o estabelecimento dos limites fronteiriços entre as nações e os direitos da navegação, por exemplo, foi criada a Primeira Conferência Internacional de Washington em 1889. Assim como suas antecessoras, nenhum Estado aprovou os pontos deliberados no evento. A primeira organização confederativa que pretendia estabelecer as relações entre os países para garantir uma convivência pacífica e um tribunal de arbitragem que obteve êxito foi a Primeira Conferência Internacional de Haia, realizada na Holanda em 1889 e composta por representantes de vinte e quatro países.

Posteriormente, houve uma outra conferência em 1907. O terceiro evento, que ocorreria em 1915, foi cancelado por conta da Primeira Guerra Mundial (1914-1918). A criação da Sociedade das Nações (1919), das Nações Unidas (1945), do Tratado de Roma (1958) e dos acordos integracionistas latino-americanos, a partir da década de 1960, pautou-se na experiência dos tratados pan-europeus e do pensamento unionista bolivariano.

Os diferentes projetos anfictionnicos tiveram como princípios a elaboração de uma assembleia de representantes, o respeito à independência dos Estados participantes, o desenlace dos litígios internacionais por meio da arbitragem, a renúncia aos processos de conquista, a manutenção dos espaços territoriais e a aceitação do preceito de não intervenção nos assuntos internos de cada membro. Apesar das similaridades dessas iniciativas, elas não foram idênticas. A relação entre o global e o regional é uma dessas variações. Grande parte dos pensadores aspirou a uma integração continental, já Crucé, Kant e Bolívar ressaltaram a necessidade de combinar os projetos regionais com as propostas mundiais.

O autor finda seu estudo com três conclusões gerais: a) os projetos anfictiônicos não devem ser vistos como utópicos, tampouco como projeções pacíficas; b) a proposta confederativa de Bolívar, no contexto do Congresso de Panamá de 1826, foi original frente às discussões filosófico-políticas do período; c) o ideário anfictiônico contribuiu para os processos integracionistas europeus e latino-americanos.

Germán A. de la Reza apresenta uma pesquisa original que contou com diversas fontes e uma vasta bibliografia em inglês, espanhol, latim e francês. Tais materiais foram encontrados em fundos reservados e patrimoniais das seguintes bibliotecas: Nacional da França, Nacional do México, José Ma. Lafragua da Secretaria de Relações Exteriores do México e do Congresso dos Estados Unidos. Para compreender as ideias políticas sobre os projetos confederativos na Europa e na América Latina, o autor utilizou-se do mé- 
todo analítico-sintético. A técnica analítica corresponde à heurística e a de síntese associa-se à hermenêutica. O primeiro método consiste em produzir uma problemática e selecionar documentos para solucioná-la. Já o segundo tem como finalidade evidenciar o sentido de um texto a fim de buscar as intenções de quem o produziu para responder as questões elaboradas.

O livro destina-se ao público interessado nas origens dos processos integracionistas na Europa e na América Latina, na proveniência filosófico-política do projeto unionista de Bolívar e na genealogia das discussões intelectuais referentes à pacificação entre Estados, à soberania nacional e à integração internacional. Apesar dos méritos, o trabalho carece de uma discussão mais aprofundada sobre os projetos anfictiônicos. Ademais, o autor deveria privilegiar em suas análises os aspectos culturais nas propostas integracionistas europeias e latino-americanas. Tais hiatos podem ser sanados em estudos mais amplos sobre o tema em questão.

Recebido: 15/09/2016 - Aprovado: 19/06/2017 